\title{
Personal protective equipment during the COVID-19 pandemic (Letter \#1)
}

\author{
George D. Shorten, MD, PhD
}

Received: 3 May 2020/Accepted: 4 August 2020/Published online: 7 August 2020

(C) Canadian Anesthesiologists' Society 2020

\section{To the Editor,}

Lockhart et al. have reviewed the importance and use of personal protective equipment (PPE) for anaesthesiologists and other airway managers. ${ }^{1}$ They point out that "PPE donning and doffing requires education and practice prior to their use during patient care", going on to state that " the more unfamiliar staff is with PPE, the more likely they will incorrectly don and doff it". Weissman et $a l^{2}{ }^{2}$ have expressed the need for fundamental research to inform PPE recommendations, particularly in the setting of tracheal intubation. They cite the recent work of Feldman et $a .^{3}$ who showed that, in a simulated setting, currently recommended PPE may not prevent exposure of those who perform tracheal intubation. One critical aspect of the efficacy of PPE in protecting healthcare workers (HCWs) is the manner in which donning is performed. A closer examination of training in donning and doffing PPE is warranted.

During the coronavirus disease pandemic, the circumstances under which donning and doffing of PPE is being learned, trained, and subsequently performed may be suboptimal. Although no overview exists of the training practices for donning and doffing PPE, it is likely that it is less than ideal.

This letter is accompanied by a reply. Please see Can J Anesth 2020; this issue.

It is related to letter \#2 20-00339

G. D. Shorten, MD, PhD ( $₫)$.

Department of Anaesthesia, University College Cork, Cork, Ireland

e-mail: g.shorten@ucc.ie
Ideally, in designing a training program for a new procedure, one would: 1) share a description of the procedure with "trainees" that contains unambiguous definitions of each step, and common and critical errors; 2) apply a pre-training preparation standard; 3) provide real-world materials (e.g., PPE) for repeated deliberate practice; 4) provide multiple training sessions based on performance; and 5) undertake an "exit" assessment. The "graduate trainee" would then transfer their newly acquired skills into the real world with experienced supervision.

Of course, one might argue that the current pandemic requires that prompt action is required during which perfect is the enemy of good. In fact, scientifically rigorous training methodology exists which ensures that a newly learned procedure is performed competently. The discipline of anesthesiology has been at the forefront of training to a pre-defined level of competency. ${ }^{4}$ Proficiencybased progression and other forms of metrics-based training decrease the incidence of errors amongst novice practitioners and the evidence of its consistent efficacy is particularly strong for procedural skills. ${ }^{5}$ It is possible that the difficulties in donning and doffing PPE are underestimated. Seal-testing a face mask and minimizing the risk of fogging googles are particularly amenable to error. The key resource for such training (characterisation of the procedure as steps and errors) is shareable at little or no cost. When the stakes are as high as the health and continued contribution of HCWs, we should use the best tools available, especially those that are consistently effective.

Disclosures None.

Funding statement None. 
Editorial responsibility This submission was handled by Dr. Philip M. Jones, Associate Editor, Canadian Journal of Anesthesia.

\section{References}

1. Lockhart SL, Duggan LV, Wax RS, Saad S, Grocott HP. Personal protective equipment (PPE) for both anesthesiologists and other airway managers: principles and practice during the COVID-19 pandemic. Can J Anesth 2020. DOI: https://doi.org/10.1007/ s12630-020-01673-w.

2. Weissman DN, de Perio MA, Radonovich LJ Jr. COVID-19 and risks posed to personnel during endotracheal intubation. JAMA 2020. DOI: https://doi.org/10.1001/jama.2020.6627.

3. Feldman $O$, Meir $M$, Shavit D, Idelman R, Shavit I. Exposure to a surrogate measure of contamination from simulated patients by emergency department personnel wearing personal protective equipment. JAMA 2020. DOI: https://doi.org/10.1001/jama.2020. 6633.

4. Shorten GD, De Robertis E, Goldik Z, Kietaibl S, Niemi-Murola L, Sabelnikovs O. European Section/Board of Anaesthesiology/ European Society of Anaesthesiology Consensus Statement on Competency-Based Education and Training in Anaesthesiology. Eur J Anaesthesiol 2020. DOI: https://doi.org/10.1097/EJA. 0000000000001201.

5. Kallidaikurichi Srinivasan $K$, Gallagher A, O'Brien $N$, et al. Proficiency-based progression training: an 'end to end' model for decreasing error applied to achievement of effective epidural analgesia during labour: a randomised control study. BMJ Open 2018. DOI: https://doi.org/10.1136/bmjopen2017-020099.

Publisher's Note Springer Nature remains neutral with regard to jurisdictional claims in published maps and institutional affiliations. 